\title{
The Stereotyped Task Engagement Process: The Role of Interest and Achievement Motivation
}

\author{
Jessi L. Smith \\ Montana State University
}

\author{
Carol Sansone and Paul H. White \\ University of Utah
}

\begin{abstract}
Competence-based stereotypes can negatively affect women's performance in math and science (referred to as stereotype threat), presumably leading to lower motivation. The authors examined the effects of stereotype threat on interest, a motivational path not necessarily mediated by performance. They predicted that working on a computer science task in the context of math-gender stereotypes would negatively affect undergraduate women's task interest, particularly for those higher in achievement motivation who were hypothesized to hold performance-avoidance goals in response to the threat. Compared with when the stereotype was nullified, while under stereotype threat an assigned performance-avoidance (vs. -approach) goal was associated with lower interest for women higher in achievement motivation (Study 1), and women higher (vs. lower) in achievement motivation were more likely to spontaneously adopt performance-avoidance goals (Study 2). The motivational influence of performance-avoidance goals under stereotype threat was primarily mediated by task absorption (Study 3). Implications for the stereotyped task engagement process (Smith, 2004) are discussed.
\end{abstract}

Keywords: achievement motivation, achievement goals, motivation, stereotype threat, gender

Women continue to be less likely to select and persist in science, mathematics, and related fields despite gains in preparation and increased requirements for both girls and boys prior to college. A number of hypotheses have been proposed as to why these gender differences occur, including both biological limitations and socialization pressures (e.g., Eccles, Adler, \& Meece, 1984). The focus of our research is on the role competence-based stereotypes may play. Whether or not there are real intrinsic ability differences between men and women in math and science (e.g., Benbow \& Stanley, 1980; Mullis et al., 1998; Spelke, 2005), stereotypes about these differences exist and are frequently made salient (e.g., comments by Summers, as cited in the Harvard Crimson, 2005). ${ }^{1}$

The stereotype threat literature is centered on the finding that awareness of a competence-related stereotype can, in and of itself, lead to poorer task performance (e.g., Smith \& White, 2002; Spencer, Steele, \& Quinn, 1999; C. M. Steele \& Aronson, 1995; Yopyk \& Prentice, 2005; see also Wicherts, Dolan, \& Hessen, 2005). Members of stereotyped groups feel threatened because their performance may confirm to themselves, other people, or both the negative performance expectations about the group. The resulting negative effects on performance can occur even when

Jessi L. Smith, Department of Psychology, Montana State University; Carol Sansone and Paul H. White, Department of Psychology, University of Utah.

A portion of this project was supported by a Spencer Foundation American Education Research Association Fellowship awarded to Jessi L. Smith. Data collection was made possible by an invaluable team of research assistants. We are grateful to Andrew Elliot, Kathleen Fuegen, Carol Werner, and Robert Arkin for their comments on a draft of the article.

Correspondence concerning this article should be addressed to Jessi L. Smith, Department of Psychology, Montana State University, 304 Traphagen Hall, Bozeman, MT 59717-3440. E-mail: jsismith@montana.edu women report that they do not believe the stereotypes are true (cf. Schmader, Johns, \& Barquissau, 2004).

As illustrated on the left side of Figure 1, the stereotype-performance path suggests negative competence-based stereotypes associated with women in math and science lead directly to an impairment of their performance (e.g., Shih, Pittinsky, \& Ambady, 1999; Smith \& White, 2002; Spencer et al., 1999), which, in turn, negatively affect their likelihood of selecting or persisting in the stereotyped domain (e.g., Crocker, Major, \& Steele, 1998).

The majority of stereotype threat research to date has focused almost exclusively on performance or anticipated performance as the main outcome of study (e.g., Inzlicht \& Ben-Zeev, 2003; Smith \& White, 2002; Stangor, Carr, \& Kiang, 1998; C. M. Steele \& Aronson, 1995; cf. Schmader et al., 2004; Smith \& Johnson, 2006; Wicherts et al., 2005). A focus on performance outcomes, although important, misses a critical issue. That is, even when performance is high, a person's motivation to choose or persist at a task may be affected by stereotypes in the situation (e.g., Bleeker \& Jacobs, 2004; Seymour \& Hewitt, 1997). Certainly, repeated negative performance outcomes may contribute to lower motivation to select or persist in math- and science-related tasks, but we believe that there are potential alternative pathways between knowledge of competence-related stereotypes and negative motivational outcomes (Schmader et al., 2004). In the next sections, we review the stereotyped task engagement process (STEP), whether and how the

\footnotetext{
${ }^{1}$ While addressing the National Bureau of Economic Research, Lawrence Summers (President of Harvard University) stated, "in the special case of science and engineering, there are issues of intrinsic aptitude [between men and women], and particularly of the variability of aptitude, and ... those considerations are reinforced by what are in fact lesser factors involving socialization and continuing discrimination" (comments by Summers, as cited in the Harvard Crimson, 2005).
} 


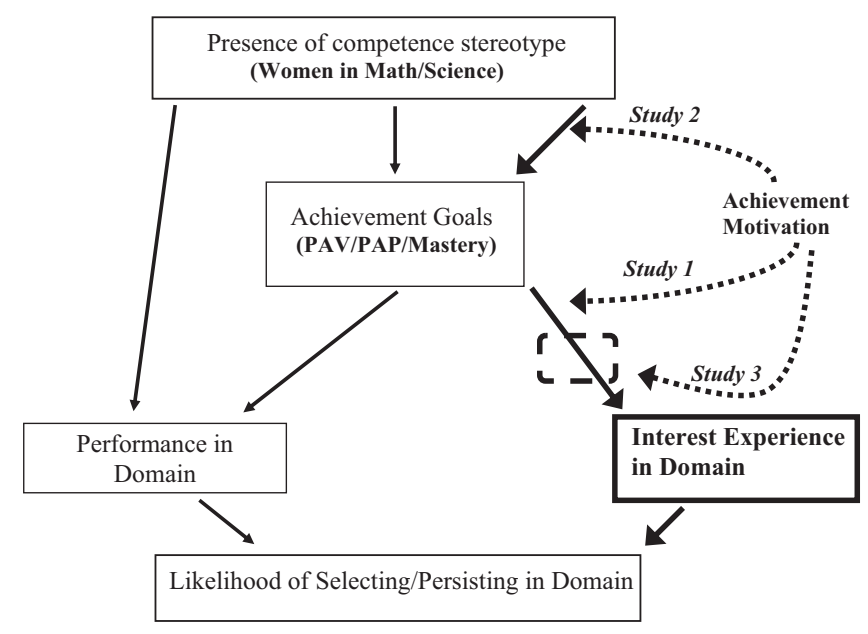

Figure 1. Effects of negative stereotypes about women in math and science on women's likelihood of selecting or persisting in math and science careers. The left side of the figure represents the performance pathway typically discussed; the bolded right side of the figure represents the proposed interest pathway, with the hypothesized moderation by individual differences in women's achievement motivation. Study 1 examines the moderation between achievement goals and interest, Study 2 examines the moderation between the salience of stereotypes and spontaneous adoption of achievement goals, and Study 3 examines potential mediating processes. PAV $=$ performance-avoidance goal; PAP $=$ performanceapproach goal.

experience of interest may come into play in this process, and how individual differences in achievement motivation may moderate this process.

\section{The STEP Model}

The STEP model (Smith, 2004; see also Smith, 2006) was originally formulated to link research on stereotype threat and achievement goal theory, as a way to begin to understand how stereotype threat might lead to lower performance in the stereotyped domain. The model uses the tripartite goal framework described by Elliot and colleagues (e.g., Cury, Elliot, Sarrazin, Fonseca, \& Rufo, 2002; Elliot \& Church, 1997; Elliot, Shell, Henry, \& Maier, 2005; Harackiewicz, Barron, Pintrich, Elliot, \& Thrash, 2002; see also Skaalvik, 1997). Before detailing how these goals may be elicited and their effects when working on a stereotyped task, we briefly define the three kinds of achievement goals proposed by this framework.

Mastery goals, defined as wanting to develop competence (e.g., I want to understand computer science), have beneficial effects on long-term learning as well as immediate and long-term interest in the task (e.g., Elliott \& Dweck, 1988; Grant \& Dweck, 2003). Mastery goals rely on individual, flexible standards of achievement (Dweck \& Elliott, 1983). Performance goals, on the other hand, rely on normative, rigid standards of achievement (Dweck \& Elliott, 1983) and can be further distinguished by an avoidanceapproach orientation.

Performance-avoidance goals are defined as wanting to avoid demonstrating incompetence (e.g., Elliot \& Church, 1997; Wolters, 2004; e.g., I want to avoid failing the computer science task) and often have negative effects on learning and motivation (e.g., Elliot \& Harackiewicz, 1996; Elliot et al., 2005). In contrast, effects of performance-approach goals on performance and motivation appear to depend both on the context and on individual differences. A performance-approach goal is defined as wanting to demonstrate competence in comparison to others (e.g., Elliot \& Church, 1997; e.g., I want to do the best on the computer science task) and often is associated with positive effects on learning in the college classroom (e.g., Harackiewicz et al., 2002). These goals have also been associated with positive, null, or negative effects on interest, depending on other individual or contextual factors (e.g., Elliot \& McGregor, 2001; Harackiewicz \& Elliot, 1993; Wolters, 2004; cf. Linnenbrink, 2005).

According to the STEP model, the presence of a stereotype could lead to negative performance effects through the adoption of a performance-avoidance goal (see the middle path in Figure 1). Because the stereotype conveys failure as the expectation for members of the person's group, the STEP model suggests that the person would therefore be more likely to adopt a goal of avoiding the demonstration of incompetence (Smith, 2006). As a result, the negative performance effects associated with performanceavoidance goals would be more likely to occur.

\section{A New Emphasis on the Experience of Interest}

Motivation, particularly an individual's experience of interest, may be the best predictor of long-term persistence in a particular educational domain (e.g., Harackiewicz, Barron, \& Elliot, 1998; Tauer \& Harackiewicz, 2004; see also Dweck \& Elliott, 1983). Interest, then, can act as an immediate motivational source of moment-to-moment action (immediate, situational interest), which may translate to commitment to and future intent to engage in the activity (future interest; Sansone \& Harackiewicz, 1996). As illustrated by the far right paths in Figure 1, the present research suggests that the previously identified effects of the presence of competence-related stereotypes on the adoption of performanceavoidance goals may also have important implications for how interesting the person comes to feel the domain-related task is or will be. We suggest that the interest-related pathways may be particularly important when the question is one of long-term selection and persistence in a field (Harackiewicz et al., 2002; Morgan, Isaac, \& Sansone, 2001; Sansone \& Thoman, 2005). Some stereotyped individuals appear to have competence but are still not motivated to do domain-related tasks (e.g., Dweck \& Elliott, 1983; Seymour \& Hewitt, 1997), suggesting motivation is an important variable to investigate, particularly among individuals who are achievement oriented. Thus, we investigated the impact of stereotypes on motivational factors by updating the STEP model to include how stereotypes and the achievement goals they elicit affect intrinsic motivation (defined as the sought, anticipated, or actual experience of interest) and how this process may be moderated by achievement motivation.

One major hypothesis of the present research, then, is that stereotyped tasks may become less interesting for individuals threatened by the stereotype because of the adoption of performance-avoidance goals. Moreover, competence stereotypes appear to be most threatening for individuals who care about achieving in general and/or achieving in the specific domain (e.g., Leyens, Desert, Croizet, \& Darcis, 2000). Thus, we further hypothesize that 
such stereotypes may have a greater impact on interest for individuals higher in achievement motivation compared with those lower in achievement motivation.

\section{Role of Achievement Motivation}

By definition, an individual higher in achievement motivation is characterized as someone who "aspires to accomplish difficult tasks; maintains high standards and is willing to work toward distant goals; responds positively to competition; willing to put forth effort to attain excellence" (Jackson, 1974/1999, p. 6). Individuals higher and lower in achievement motivation appear to be different in terms of the kinds of achievement goals they spontaneously adopt in the same situation. Individuals higher in achievement motivation are more likely than those lower in achievement motivation to endorse all achievement goals: mastery, performance-approach, and performance-avoidance goals (Elliot \& McGregor, 2001). Thus, if the presence of competence-related stereotypes leads to the adoption primarily of performanceavoidance goals at the expense of other achievement goals, then the functions that the other kinds of goals typically serve for individuals higher in achievement motivation will not be served (e.g., Harackiewicz et al., 2002; Linnenbrink, 2005; Pintrich, 2000; Wolters, 2004).

One important function of the different kinds of achievement goals is the degree of interest that individuals may experience while working toward them. Previous research suggests that even when individuals adopt the same goals, these goals may relate to interest differently as a function of an individual's achievement motivation (Sansone \& Thoman, in press). For example, Harackiewicz and Elliot (1993) found that individuals higher in achievement motivation found a task more interesting when assigned performance-approach goals, whereas individuals lower in achievement motivation found the same task more interesting when assigned mastery goals. Later research by Barron and Harackiewicz (2001) suggested that performance-approach and mastery goals may have different effects on interest as a function of achievement motivation and whether the goals are spontaneously adopted or assigned. In particular, for both high and low achievement-oriented individuals, spontaneously adopted mastery goals were associated with greater interest for a math activity. In contrast, when assigned either mastery or performance-approach goals, Barron and Harackiewicz replicated the pattern found previously by Harackiewicz and Elliot.

Although previous research provides some suggestions for how achievement motivation may moderate the impact of performanceapproach and mastery goals on interest, much less research has been done examining performance-avoidance goals and interest. Elliot and Harackiewicz (1996) found that assigned performanceavoidance goals were associated with lower interest as compared with assigned performance-approach, mastery, or performanceneutral goals, but these authors did not assess individual differences in achievement motivation. One possibility, therefore, is that when assigned performance-avoidance goals under conditions of stereotype threat, both individuals higher and lower in achievement motivation will experience lower interest, with the key difference being that individuals higher in achievement motivation would be more likely to spontaneously adopt performanceavoidance goals in those situations. Another possibility is that individuals higher and lower in achievement motivation may experience different levels of interest even when assigned the same performance-avoidance goal. Understanding the role of achievement goals and their interaction with an individual's achievement motivation on feelings of intrinsic motivation for a stereotyperelevant task is important because extant research suggests that individuals of all ability levels, but differing levels of achievement motivation, will interact with, experience, and perform tasks differently depending on the type of goal they spontaneously adopt or are assigned to adopt (e.g., Barron \& Harackiewicz, 2001; Elliot \& McGregor, 2001; Harackiewicz et al., 1998; Linnenbrink, 2005; Nicholls, 1984).

\section{Project Overview}

This project examined the role of interest and achievement motivation in understanding women's lower motivation to select and persist in domains for which negative competence stereotypes about women exist. Our conceptual framework for the studies is illustrated in bold on the right side of Figure 1. In this extension of the STEP model, we focused on the role of math and gender stereotypes on women's motivation for a computer science task. Although stereotype threat research is replete with studies dealing with gender and mathematical tasks, it is possible that the effects of gender and math stereotypes also influence math-related fields and tasks, such as computer science. Previous research confirms that individuals see math ability as a necessary component of computer science. There is a perceived link between math ability and computer ability (e.g., Carver, 2000; Smith, Morgan, \& White, 2005). However, computer science also involves skills and abilities that are not necessarily defined by or limited to mathematics, such as logical thinking, creative design, and the understanding of human-computer dynamics. Thus, if the awareness of the gender and math stereotype can influence interest in a novel computer science task, it suggests that these competence-based stereotypes may have a wider detrimental effect. The impact of the gender and math stereotype may contaminate the experience of domains that are not defined solely by mathematics.

Because our focus is on how initial experiences with tasks in novel but stereotyped domains can lead to lower likelihood of future engagement in these domains, we examined our questions among women at the beginning of their college careers who had not yet committed to pursuing (or not pursuing) a degree in computer science. In addition, we selected as study participants women who were not enrolled in a computer science course because current computer science students may have already overcome any detrimental effects that stereotypes have on domain interest, or they may have had greater interest in computer science.

In Study 1, we investigated the relation between performanceavoidance achievement goals and interest for women high in achievement motivation. Do performance-avoidance goals in the presence of a stereotype negatively impact intrinsic motivation, relative to the assignment of other kinds of achievement goals and relative to a context in which women are told that the stereotype is invalid? It was predicted that women high in achievement motivation faced with a gender stereotype and a performanceavoidance goal would experience low intrinsic motivation for the task, compared with those who faced the stereotype but had a performance-approach goal. In Study 2, we investigated the mod- 
eration by achievement motivation of the relationship between stereotypes and spontaneous adoption of achievement goals. That is, do individuals high and low in achievement motivation spontaneously adopt different achievement goals in the presence of a stereotype? This is important toward understanding goal origin as a function of stereotype threat and achievement motivation. It was predicted that women higher in achievement motivation, compared with those lower in achievement motivation, may be more likely to spontaneously adopt performance-avoidance goals in a stereotype context. Finally, in Study 3, we investigated potential mediators of the impact achievement goals have on intrinsic motivation in the presence of a stereotype. If goal adoption is influenced by the presence of a stereotype, which, in turn, impacts intrinsic motivation, then what process variables may account for these effects? This is important if one wants to attempt interventions that may enhance interest for those stigmatized in the domain. To begin to explore the motivational process, we compared a performancerelated process variable (perceived competence) with an intrinsic motivation process variable (task absorption) to determine whether one process variable was more likely than the other to be involved or whether both variables were involved. We also wished to examine whether the potential mediating process differed as a function of achievement motivation.

\section{Study 1}

As the first phase of investigating the role of achievement motivation in stereotyped individuals' task experience, we tested whether an achievement goal in the presence of a stereotype influenced intrinsic motivation. Intrinsic motivation is often assessed at two levels: as immediate interest in a task and as future interest in engaging in a similar task. The immediate situationbased experience of interest does not necessarily translate to future intentions to engage in the task, which instead depends on whether individuals see the situational interest as something that is likely to occur in future engagements (e.g., Isaac, Sansone, \& Smith, 1999). To see whether immediate situation-based interest was likely to affect future interest, we measured both. It has been shown that both immediate and future interest are positively influenced by performance-approach and mastery goals (e.g., A. J. Elliot \& McGregor, 2001; E. S. Elliott \& Dweck, 1988; Grant \& Dweck, 2003; Wolters, 2004), whereas performance-avoidance goals tend to have a negative impact on immediate interest (e.g., A. J. Elliot \& Harackiewicz, 1996). However, these effects have not been tested directly in the face of a stereotype. We proposed that assigning performance-approach goals may attenuate any negative effects stereotypes may have on motivation but that performanceavoidance goals may heighten the negative effects. Our predictions for mastery goals were more tentative. Previous research shows that assigned mastery goals may not lead to greater interest for individuals higher in achievement motivation because these individuals approach tasks already holding mastery goals, and as such, assigning a mastery goal may have no incremental effect (Barron \& Harackiewicz, 2001; Harackiewicz \& Elliot, 1993). We thus examined whether this pattern holds true no matter the salience of a competence-related stereotype, or whether the stereotype context moderates this previously found effect. To examine these hypotheses, we manipulated both the relevance of a gender stereotype and the assigned achievement goal for a computer science task and then measured interest for women high in achievement motivation.

\section{Method}

\section{Participants}

In a large mass testing session, potential participants completed a battery of surveys, including the well-validated, 16-item Achievement Motivation subscale of the Personality Research Form (Jackson, 1974/1999; example item: "I would work just as hard whether or not I had to earn a living"). This scale has been shown to have good test-retest reliability among college students (reliability coefficient $\alpha=.80$ ) and has been validated with a variety of convergent and discriminant scales (e.g., Jackson, 1974/ 1999). Scores on this measure can range from 0 (not at all achievement motivated) to 16 (extremely achievement motivated). Normative data provided by Jackson (1974/1999) show a mean achievement motivation score of $10.00(S D=3.41)$ for women in college, and a mean score of $9.39(S D=3.23)$ for girls in the 12 th grade. Our mass testing participants scored within this range, and female participants scoring above the mass testing sample median (10.52) were recruited for participation. A total of 97 females (mean age $=21.3$ years, $S D=5.1$ years; $92.3 \%$ reported freshmen and sophomore status; $91.2 \%$ reported Caucasian; $3.1 \%$ reported African American; 0.7\% reported Native American; 0.7\% reported Hispanic; $2.3 \%$ unreported) enrolled in introductory psychology classes at a large Midwestern university participated in exchange for partial course credit. Participants were specifically recruited if they said (in mass testing) that they were undecided about their college major.

Participants were randomly assigned to one of 8 conditions in a 2 (stereotype threat vs. nullified stereotype) $\times 4$ (performanceavoidance goal vs. performance-approach goal vs. mastery goal vs. no goal provided) design. As expected, achievement motivation among our participants was relatively high and did not differ by conditions (all $p \mathrm{~s}>.36$ : stereotype threat and no goal, $M=11.70$; stereotype threat and performance-approach goal, $M=12.38$; stereotype threat and performance-avoidance goal, $M=12.00$; stereotype threat and mastery goal, $M=11.55$; nullified stereotype and no goal, $M=12.31$; nullified stereotype and performanceapproach goal, $M=11.77$; nullified stereotype and performanceavoidance goal, $M=12.54$; nullified stereotype and mastery goal, $M=11.36$ )

\section{Procedure}

In small sessions, participants were met by a female experimenter, given a set of headphones, and then seated individually in front of a computer (separated by partitions). All directions and manipulations were prerecorded and controlled by the computer; thus, the experimenter was unaware of conditions. Participants first listened to (and read) a recorded tutorial by a male narrator explaining the upcoming task, called the computing aptitude assessment tool (CAAT). The tutorial was presented in a Web-style format and consisted of text and images describing the history of computer programming, the definitions of various terms used in computer programming (e.g., Boolean algebra number systems and algorithm), and an example of computer programming code 
(e.g., FREQUENCIES VARIABLES = income /NTILES = 2 /STATISTICS = MEAN MEDIAN SKEWNESS SESKEW /HISTOGRAM NORMAL /ORDER ANALYSIS.) and data output. Participants then responded to short-answer questions about the material in the tutorial (e.g., what two codes can be used to end a program?) to ensure that everyone had the same knowledge before receiving the manipulations and advancing to the task.

Next, participants were directed to a fictitious one-page journal article used to explicitly remind the participants of the stereotype that men are superior to women in mathematic domains (manipulations adopted from Smith \& Johnson, 2006; Smith \& White, 2002; see also Spencer et al., 1999). Half the participants who were given the article then heard a narrator report that our own past investigations had found similar results in using the CAAT (stereotype threat). The other half heard that our past investigations showed that there were no gender differences on the CAAT (nullified stereotype).

Participants in the two performance goal conditions then read (and heard) an overview of the study:

The purpose of this project is to collect data on computing aptitude by comparing beginning college students to one another in their ability to use mathematics skills to do computing. This aptitude tool will really show what you can do.

Participants assigned to the performance-avoidance goal condition then heard

In our work we have found that some students stand out because they do quite poorly on the CAAT. For instance, if you do worse on the CAAT than a majority of University students, you will demonstrate that you have poor computing aptitude.

Participants in the performance-approach condition heard

In our work we have found that some students stand out because they do quite well on the CAAT. For instance, if you do better on the CAAT than a majority of University students, you will demonstrate that you have good computing aptitude.

(Manipulations were modeled after Elliot \& Harackiewicz, 1996; Elliott \& Dweck, 1988.) Participants in the mastery goal condition were told working on the CAAT would provide them with an opportunity to really learn and understand the information, whereas participants in the condition in which no goal was provided did not hear any additional overview information.

After the stereotype and goal manipulations, all participants listened to a description of the CAAT describing algorithms and their different uses, such as games, text processing, simulation, modeling, and mathematical data analysis, with the latter being the emphasis for their upcoming assessment task. They were then given 15 min to work on the CAAT (described below). Participants did not receive any feedback regarding their performance. (In fact, the computer was unable to record performance in this study.) After time had expired, participants rated three items tapping their interest in the task (e.g., "This task is fun to do"; $\alpha=.82$; see Sansone, Wiebe, \& Morgan, 1999) and two items assessing their future interest in learning more about computer-related topics (e.g., "How likely would you be to learn more on programming in the future?”; $\alpha=.89$ ). All items were rated on a $1-7$ scale.
A manipulation check was then administered to check whether participants could correctly recall the gist of the stereotype article and the task overview given to them at the beginning of the study. Specifically, participants were asked to freely recall the main point of the article and anything they had been told about our own lab research on the topic (threat manipulation) and to identify (from a list) what their instructions (goal manipulation) had been for the task. In no case did participants misidentify their goal condition and/or fail to recall the stereotype. Lastly, participants were thanked and debriefed.

\section{CAAT Task}

Modeled after chapter 1 of Graham's (1985) Introduction to Computer Science textbook, the CAAT was designed to simulate a homework assignment in which students are to do two things: identify how a set of outputs was created and identify errors in constructed programs. Specifically, the CAAT was presented to participants as assessing two aspects in computing. It stated

First, it is important to be able to use computing logic to look at something, such as output, to try and determine what types of codes were used to produce that output. Second, it is important to be able to use that same logic to figure out why a program doesn't work, sometimes called de-bugging.

Participants were then presented with an output file (created by a frequency analysis) and a list of codes, only one of which would create the output. Next, participants were presented with a code and a list of error messages that appeared after the code was run. Participants were asked to debug the code by identifying the errors (e.g., missing a "BY" extension and missing a "/"). Pilot testing found the CAAT to be perceived as difficult and uninteresting (see also Smith \& Johnson, 2006, for more CAAT details).

\section{Results and Discussion}

A 2 (stereotype threat vs. nullified stereotype) $\times 4$ (performance-avoidance goal vs. performance-approach goal vs. mastery goal vs. no goal provided) analysis of variance (ANOVA) was performed on reported immediate interest for this sample of achievement-motivated women. Results yielded a significant interaction between stereotype condition and goal condition, $F(3$, $89)=3.73, p=.01, R^{2}=.14$. As seen in Table 1 , when achievement-motivated women worked on a computer programming task after being exposed to the math-gender stereotype, they reported the least immediate interest in the task when assigned performance-avoidance goals and the most immediate interest when assigned performance-approach goals. In contrast, when first told that the math-gender stereotype has been shown not to apply in this situation, women in the condition with no assigned goal reported the highest levels of immediate interest.

Follow-up simple effects analyses also indicated that in the context of stereotype threat, women reported similar levels of interest in the condition in which no goal was assigned and the assigned performance-avoidance goal condition, with women in the assigned mastery goal condition reporting interest levels between these two conditions and the assigned performanceapproach goal condition. This pattern suggests that under no goal conditions, women high in achievement motivation may be spon- 
Table 1

Study 1: Mean Immediate Interest and Future Task Interest Ratings as a Function of Stereotype and Goal Condition for Women Higher in Achievement Motivation

\begin{tabular}{|c|c|c|c|c|c|c|c|c|c|c|c|c|}
\hline \multirow{2}{*}{$\begin{array}{l}\text { Stereotype } \\
\text { condition }\end{array}$} & \multicolumn{3}{|c|}{ No goal } & \multicolumn{3}{|c|}{ Mastery } & \multicolumn{3}{|c|}{ PAP } & \multicolumn{3}{|c|}{ PAV } \\
\hline & $n$ & $M$ & $S D$ & $n$ & $M$ & $S D$ & $n$ & $M$ & $S D$ & $n$ & $M$ & $S D$ \\
\hline \multicolumn{13}{|c|}{ Interest } \\
\hline Stereotype threat & 12 & $2.83_{\mathrm{b}}$ & 1.08 & 12 & $3.17_{\mathrm{a}, \mathrm{b}}$ & 1.34 & 12 & $3.87 \mathrm{a}$ & 1.54 & 12 & $2.53_{\mathrm{b}}$ & 0.95 \\
\hline Nullified stereotype & 13 & $3.50_{\mathrm{b}}$ & 1.48 & 12 & $2.58_{\mathrm{a}, \mathrm{c}}^{\mathrm{a}, \mathrm{O}}$ & 1.09 & 12 & $2.43_{\mathrm{c}}^{\mathrm{a}}$ & 0.95 & 12 & $3.03_{\mathrm{b}, \mathrm{c}}^{\mathrm{D}}$ & 1.39 \\
\hline \multicolumn{13}{|c|}{ Future interest } \\
\hline Stereotype threat & & 2.45 & 1.38 & & 3.56 & 2.04 & & 4.46 & 1.66 & & 2.80 & 1.36 \\
\hline Nullified stereotype & & 4.16 & 1.77 & & 3.73 & 1.98 & & 3.77 & 1.89 & & 3.42 & 0.91 \\
\hline
\end{tabular}

Note. Interest row and column means not sharing a subscript differ at $p<.05$, with the exception of the mastery goal versus no goal comparison in the nullified threat condition, in which $p=.057$. Simple effects are not provided for the future interest means because the interaction effect was nonsignificant. Scores could range from 1 to 7 . PAP = performance-approach goal; PAV = performance-avoidance goal.

taneously adopting a performance-avoidance goal. This suggestion was more directly examined in Study 2.

\section{Effects on Future Interest}

A 2 (stereotype threat vs. nullified stereotype) $\times 4$ (performance-avoidance goal vs. performance-approach goal vs. mastery goal vs. no goal provided) ANOVA was performed on future interest. Results yielded a nonsignificant interaction between stereotype condition and goal condition, $F(3,89)=2.35, p=.08$, $R^{2}=.13$. Examination of the means (see Table 1) showed a similar, but not statistically significant, pattern to the interest results. Future interest was significantly correlated with task interest, $r(97)=.44, p=.001$. These results suggest that women's immediate experience of the task contributes to the likelihood that they will select or persist on similar tasks in the future.

\section{Summary}

The results from Study 1 suggest that one reason that women who care about achieving may be particularly vulnerable to the negative effects of salient stereotypes is that they may be more likely to spontaneously adopt performance-avoidance goals, which were associated with lower interest in the task. Although the results from Study 1 support the suggestion that performanceavoidance goals are associated with lower interest, the results do not address whether achievement-oriented women are more likely to spontaneously adopt performance-avoidance goals under stereotype threat. In Study 2, therefore, we measured adopted goals and included women who are characteristically less likely to value achievement as a comparison.

In addition, results from Study 1 suggest that when the stereotype was salient, assigning a performance-approach goal to individuals high in achievement motivation enhanced interest in the task. Yet, assigning a mastery goal in this same condition did not result in enhanced interest. Our results are similar to findings by Harackiewicz and colleagues (Barron \& Harackiewicz, 2001; Harackiewicz \& Elliot, 1993), who suggested that this pattern of (null) mastery goal findings illustrates the important role of the spontaneous goals individuals hold prior to being assigned a particular goal. One possibility is that the stereotype context may change not only whether individuals high in achievement motivation hold performance-avoidance goals but also whether they hold mastery and performance-approach goals. In Study 2, we examined the extent to which all three kinds of goals are spontaneously adopted and included a comparison condition in which nothing was explicitly said about the stereotype in any way.

\section{Study 2}

In Study 2, we investigated the suggestion from Study 1 that women higher in achievement motivation may be more likely to spontaneously adopt performance-avoidance goals when working in a stereotype threat context than when working on the same task under conditions in which the stereotype is said not to apply. In addition to examining whether these individuals are more likely to adopt performance-avoidance goals, a secondary question was whether they are less likely to adopt performance-approach or mastery goals (Barron \& Harackiewicz, 2001). We also compared the patterns of spontaneous goal adoption of higher achievementoriented and lower achievement-oriented women. As noted previously, women higher and lower in achievement motivation may experience different levels of interest in a task under stereotype threat conditions because they spontaneously adopt different kinds of achievement goals, in addition to possibly responding to the same goal differently.

\section{Method}

\section{Participants}

Potential participants enrolled in introductory classes (i.e., psychology, sociology, environmental science) at two large Midwestern and Rocky Mountain universities completed Jackson's (1974/ 1999) achievement motivation scale in large mass testing sessions. A total of 65 female participants scoring above or below the sample median (10.01) were recruited by telephone for participa- 
tion. ${ }^{2}$ Five participants were excluded from analyses for incorrect responses to the manipulation check. In addition, 2 Asian American participants were excluded from analyses to ensure that the gender stereotype was not confounded with positive (math performance) ethnicity-related stereotypes (Shih et al., 1999). Data from the remaining 58 participants $(63.5 \%$ reported freshmen status; 94\% Caucasian, 6\% Hispanic) are reported below. Participants were recruited for participation in this study if they were undecided about computer science specifically as their major (neither strongly leaning toward or against). Participants were blocked on achievement motivation and randomly assigned to one of three stereotype conditions in a 2 (high achievement motivation vs. low achievement motivation) $\times 3$ (stereotype threat vs. nullified stereotype vs. nothing said about stereotypes) between-participants design.

\section{Procedure}

The same procedures from Study 1 were used with some exceptions: Participants in the math-gender stereotype threat and nullified stereotype condition were again explicitly reminded of the stereotype that men are superior to women in mathematic domains. However, for this study, a condition in which nothing was said about the stereotype condition was added, in which participants were not given any information about stereotypes. It was unclear whether simply working on the math-related task was enough to induce an implicit stereotype threat (e.g., Nosek, Banaji, \& Greenwald, 2002; Smith \& Johnson, 2006; Smith \& White, 2002) or whether working on the task with no stereotype information would serve as a control condition (e.g., Aronson et al., 1999; Schmader \& Johns, 2003).

After the stereotype manipulations, all participants listened to the overview of the CAAT described in Study 1 (but no achievement goal information was provided). Participants were then given 15 min to work on the CAAT. Participants did not receive any feedback regarding their performance. After time had expired, participants completed an open-ended thought-listing measure (used to assess goals). A manipulation check was administered, and participants were thanked and debriefed.

\section{Achievement Goal Adoption}

Because we were interested in the goals (and patterns of goals) that individuals spontaneously adopted, we used a nondirected, open-ended method so that the measure did not itself suggest goals to individuals (e.g., Visser, Krosnick, \& Lavrakas, 2000). Participants were asked to "write any thoughts and feelings you are having or were experiencing before you were signaled to stop working on the CAAT." Following the guidelines articulated by Elliot and Sheldon (2002), a coding scheme was then developed by using published self-report achievement goal survey items (Elliot \& Church, 1997; Elliot \& McGregor, 2001) to code the spontaneously listed thoughts. These thoughts were coded by two judges (with $93.6 \%$ agreement; disputes were settled by Jessi L. Smith) for the presence of performance-avoidance related thoughts (e.g., "I worry about the possibility of getting a bad grade," and "I just want to avoid doing poorly"), performance-approach related thoughts (e.g., "It is important to me to do better than the other students," and "I was striving to demonstrate my ability relative to others"), and mastery-related thoughts (e.g., "I prefer material that really challenges me," and "I prefer material that arouses my curiosity, even if it is difficult"). Thoughts unrelated to goals were coded as "other." This procedure of coding open-ended thought listings for the presence of achievement goals has been shown to yield results similar to those obtained with scale measures of goals (e.g., Harackiewicz, Barron, Carter, Lehto, \& Elliot, 1997). Participants were free to mention more than one thought, and all thoughts listed were coded. A total of 225 thoughts were coded, with $44.4 \%$ falling into at least one of our goal-related categories. Approximately $41 \%$ of participants listed at least 1 performanceavoidance related thought, and the observed range was $0-3$. Approximately $52 \%$ of participants listed at least 1 performanceapproach related thought, and the observed range was $0-4$. However, only approximately $12 \%$ of participants listed at least 1 mastery-related thought, and the observed range was $0-3$.

\section{Results and Discussion}

First, we wanted to ensure that achievement motivation did not differ between conditions, and it did not, $F(2,55)=1.58, p=.22$, $R^{2}=.05$. Achievement motivation of participants randomly assigned to the stereotype threat condition (overall, $M=9.95, S D=$ 2.31; high achievement motivation, $M=11.64$; low achievement motivation, $M=7.89$ ) was statistically similar to that of participants randomly assigned to the nullified stereotype condition (overall, $M=9.43, S D=2.54$; high achievement motivation, $M=$ 11.33; low achievement motivation, $M=7.36$ ) and participants randomly assigned to the condition in which nothing was said about stereotypes (overall, $M=10.86, S D=2.41$; high achievement motivation, $M=12.20$; low achievement motivation, $M=$ $8.20)$.

\section{Effects on Achievement Goal Adoption}

The focus of Study 2 was to examine whether women higher and lower in achievement motivation were differentially likely to spontaneously adopt performance-avoidance goals when the math-gender stereotype was salient. It was therefore desirable to test whether participants subjected to stereotype threat had numbers of spontaneous performance-avoidance, performanceapproach, and mastery goal-related thoughts comparable to those of participants for whom the stereotype was nullified, and if this differed as a function of achievement motivation. Because not all participants had thoughts listed in all categories, we conducted three separate 2 (high achievement motivation vs. low achievement motivation) $\times 3$ (stereotype threat vs. nullified stereotype vs. nothing said about stereotypes) ANOVAs, with the number of each

\footnotetext{
${ }^{2}$ Median splits were computed separately for each study by using the mass testing sample to determine cutoffs. As such, the designation of high and low achievement motivation was slightly different for each study. However, analyses showed that very few participants classified as high in one study were classified as low in another study (and vice versa). Nevertheless, we reran analyses in all three studies deleting any cases in which this occurred, and we also reran analyses using the grand median cutoff across studies (the median from all three mass testing samples); results were unchanged. Thus, to maintain the integrity of the original data, we classified participants according to their respective sample's cutoffs.
} 
of the three goal-related thoughts serving as the dependent variables. To adjust for the possibility of capitalizing on chance from conducting the three goal analyses separately, we adopted a Bonferroni correction yielding an alpha equal to .02.

Performance-avoidance-related thoughts. As predicted, a significant interaction emerged between achievement motivation and stereotype condition for the number of performance-avoidance related thoughts, $F(2,52)=7.47, p=.001, R^{2}=.25$. Although overall reports of performance-avoidance goals were low, follow-up simple effects analyses revealed that higher achievement motivation participants subjected to stereotype threat spontaneously cited relatively more performance-avoidance related thoughts compared with lower achievement motivation participants in the same condition and higher achievement motivation participants in the nullified stereotype condition (see Table 2). Low achievement motivation participants were most likely to cite performance-avoidance related thoughts in the nullified stereotype condition compared with high achievement motivation participants in the same condition. Results for the condition in which nothing was said about stereotypes showed high achievement motivation participants reporting a similar number of performance-avoidance related thoughts compared with high achievement motivation participants in the stereotype threat condition, supporting Smith and White's (2002) finding that an implicit stereotype exists in mathrelated contexts, such that even when no information about stereotypes is explicitly presented, the situation itself can trigger stereotype activation.

Performance-approach-related thoughts. Tests of the between-participants effects indicated a main effect of achievement motivation on performance-approach related thoughts, such that across conditions, low achievement motivation participants were relatively more likely to report performance-approach related thoughts compared with high achievement motivation participants, $F(1,52)=10.24, p=.002, R^{2}=.29$. However, this main effect was qualified by an interaction with stereotype condition, $F(2$, $52)=4.09, p=.02, R^{2}=.30$. As seen in Table 2, simple effects analyses showed that highly achievement-motivated women did not significantly vary in spontaneously generated performanceapproach related thoughts as a function of stereotype condition. For women lower in achievement motivation, however, stereotype condition was important, such that they were least likely to spontaneously adopt performance-approach goals when the mathgender stereotype had been nullified and most likely when the stereotype was explicit or nothing was said. In comparing women higher and lower in achievement motivation, women lower in achievement motivation were significantly more likely to hold performance-approach goals under stereotype threat or nothing said conditions. Although there was no basis for generating predictions about this pattern a priori, previous research and Study 1 results suggest that although performance-approach goals may be associated with greater interest for high achievement motivation participants, this may not be the case for low achievement motivation participants (e.g., Harackiewicz \& Elliot, 1993) because of the role of performance pressure (e.g., Senko \& Harackiewicz, 2005). Thus, stereotypes may be associated with lower interest for both high achievement motivation participants and low achievement motivation participants, but through different achievement goals. We examined this possibility in Study 3.

Mastery-related thoughts. Given the overall low frequencies of mastery-related thoughts, analyses were not conducted. However, it is noteworthy that participants who did list at least one mastery-related thought were primarily high achievement motivation participants in the nullified stereotype condition (see Table 2).

Table 2

Study 2: Mean Number of Spontaneous Goal-Related Thoughts as a Function of Achievement Motivation and Stereotype Condition

\begin{tabular}{|c|c|c|c|c|c|c|}
\hline \multirow[b]{3}{*}{ Stereotype condition } & \multicolumn{6}{|c|}{ Achievement motivation } \\
\hline & \multicolumn{3}{|c|}{ Higher } & \multicolumn{3}{|c|}{ Lower } \\
\hline & $n$ & $M$ & $S D$ & $n$ & $M$ & $S D$ \\
\hline \multicolumn{7}{|c|}{ Performance-avoidance related thoughts } \\
\hline Stereotype threat & 10 & $0.74_{a}$ & 0.39 & 9 & $0.34_{b}$ & 0.25 \\
\hline Nothing said about stereotypes & 10 & $0.68_{\mathrm{a}}$ & 0.64 & 9 & $0.21_{\mathrm{b}}$ & 0.23 \\
\hline Nullified stereotype & 10 & $0.25_{\mathrm{b}}$ & 0.25 & 10 & $0.63_{\mathrm{a}}$ & 0.32 \\
\hline \multicolumn{7}{|c|}{ Performance-approach related thoughts } \\
\hline Stereotype threat & & $0.53_{\mathrm{a}}$ & 1.39 & & $2.14_{\mathrm{c}}$ & 1.32 \\
\hline Nothing said about stereotypes & & $0.84_{\mathrm{a}}^{\mathrm{a}}$ & 0.68 & & $2.27_{\mathrm{c}}^{c}$ & 1.22 \\
\hline Nullified stereotype & & $0.67_{\mathrm{a}, \mathrm{b}}$ & 0.79 & & $0.52_{\mathrm{b}}$ & 1.10 \\
\hline \multicolumn{7}{|c|}{ Mastery-related thoughts } \\
\hline Stereotype threat & & 0.00 & 0.00 & & 0.00 & 0.00 \\
\hline Nothing said about stereotypes & & 0.00 & 0.00 & & 0.20 & 0.45 \\
\hline Nullified stereotype & & 0.83 & 1.19 & & 0.09 & 0.03 \\
\hline
\end{tabular}

Note. Within goal category, row and column means not sharing a subscript differ at $p<.05$, as determined by follow-up simple effects analyses. 


\section{Summary}

The results from the first two studies suggest that interest in computer programming tasks for women who characteristically value achievement may be particularly vulnerable to math-gender stereotypes, because the stereotypes (whether made salient through explicit statement or simply by performing the gender-stereotyped task) make them more likely to spontaneously adopt performanceavoidance goals (Study 2), which are associated with lower interest under these conditions (Study 1). When achievement-motivated women were assigned performance-approach goals in the same context, however, this orientation appeared to overcome the negative effects on interest that may happen spontaneously. The results from Study 2 also suggested an intriguing but unanticipated possibility - that is, women lower in achievement motivation are more likely to adopt performance-approach rather than performance-avoidance goals when stereotypes are salient. Although performance-approach goals were beneficial for the achievementmotivated women in Study 1, previous research suggests that this might not be the case for women lower in achievement motivation (Harackiewicz \& Elliot, 1993; Senko \& Harackiewicz, 2005).

\section{Study 3}

Study 3 examined potential processes that may mediate the link between performance-avoidance goals and lower task interest for highly achievement-motivated women under stereotype threat. One possible mediating mechanism is related to the performance pathway that has been the focus of most stereotype threat research. That is, performance-avoidance goals may be associated with lowered perceived competence for these women, and lower perceived competence may result in lower interest (e.g., Cury et al., 2002; Elliot \& Harackiewicz, 1996; Elliot et al., 2005; Sansone, 1986). Alternatively, women higher in achievement motivation may experience lower interest because a performance-avoidance goal makes them more distracted while working on the task and, thus, less involved in the task (Csikszentmihalyi, 1978; Elliot \& Harackiewicz, 1996). This possibility suggests that the experience of task absorption may be a distinct yet important predictor of negative motivational effects of stereotypes.

A second purpose of Study 3 was to examine and compare this process to the process for individuals lower in achievement motivation. The results from Study 2 suggested that women higher and lower in achievement motivation may spontaneously adopt different kinds of performance goals under stereotype threat, with women lower in achievement motivation more likely to adopt performance-approach goals. However, we do not know whether the same goals are associated with similar or different effects on interest, although previous research suggests that performanceapproach goals may be associated with lower interest for individuals lower in achievement motivation. We thus examined these potential differing effects on interest, in addition to looking at the same potential mediators.

A final purpose of Study 3 was to begin to examine whether performance-avoidance goals may be associated with lower interest for women higher in achievement motivation because the avoidance orientation makes them less likely to engage in available, off-task strategies to regulate interest. Previous work by Sansone and colleagues has suggested that when faced with an uninteresting but important activity, individuals may strategically engage in actions that make performance more interesting, thereby enhancing motivation to persist (Sansone \& Smith, 2000; Sansone, Weir, Harpster, \& Morgan, 1992). However, these actions may also hinder performance, at least in the short term (Sansone \& Thoman, 2005). It is possible that because higher achievement motivation participants are more concerned with avoiding the demonstration of incompetence conveyed by the stereotype, relative to lower achievement motivation participants, they may be less willing to risk hurting performance. As a result, they may experience lowered interest.

\section{Method}

\section{Participants}

We tested a total of 75 female participants (mean age $=19.37$ years; $57.1 \%$ freshmen; $91.5 \%$ Caucasian; $4.75 \%$ Hispanic; $3.75 \%$ Asian American). Participants enrolled in introductory classes (i.e., psychology, sociology, environmental studies) at a large Rocky Mountain university were recruited by telephone to participate for extra course credit on the basis of their scores on Jackson's (1974/1999) achievement motivation scale, which was completed in a large mass testing session (sample median $=10.59$ ). Only participants who were undecided about computer science specifically as a major were recruited. Ten participants were excluded from analyses because of large amounts of incomplete data (due to experimenter error), and 4 participants were excluded because of incorrect responses on the manipulation check. In addition, 5 Asian American participants were excluded from analyses to ensure that the sample was similar to that in Study 2. Participants were blocked on achievement motivation and randomly assigned to one of two goal conditions in a 2 (high achievement motivation vs. low achievement motivation) $\times 2$ (performance-avoidance goal vs. performance-approach goal) betweenparticipants design.

\section{Procedure}

Procedures were similar to those in Study 1 and Study 2, with a few exceptions. First, to induce gender-stereotype salience for everyone before completing the task, participants were asked to complete a demographic survey that instructed them to check off their gender by marking the appropriate box (similar to procedures by C. M. Steele \& Aronson, 1995; see also Blanton, Crocker, \& Miller, 2000). Participants all heard the same overview as in Study 1 with the same manipulation of performance-avoidance and performance-approach goals. For all participants, the overview ended with a section describing an additional discussion chat room component of the CAAT (see below). Participants were informed that they were allowed to visit the chat room but that it was not required. All were then given $25 \mathrm{~min}$ to work on the extended version of the CAAT. Finally, participants completed several items including the same interest and manipulation check items used in Study 1 and additional items assessing chat room use, perceived competence, and task absorption, described below.

\section{Expanded Task}

The CAAT was expanded to include a third section, which included building a working program to generate a set of outputs 
for three given variables. A blank programming screen was displayed for participants to write their program. Second, the expanded CAAT also included an interest-enhancing strategy option. The task allowed participants the option of engaging in a relatively interesting chat room. We selected this as an exploratory operationalization of strategy use because previous research suggests that women are more likely to be people-oriented, yet mathematical-related domains such as computer science are perceived as lacking interpersonal appeal (Eccles \& Vida, 2003, as cited in Chamberlin, 2003). Indeed, domains that are congruent with interpersonal goals are perceived as more interesting to women (Morgan et al., 2001). Visiting the chat room, then, could serve as a potential strategy for women to regulate interest while working on the task. The interest-enhancing strategy appeared in the form of a hyperlink (titled Visit the Discussion Chat Room) on a continuously visible sidebar. The hyperlink connected participants to a new (sidebar) web page that contained ostensible postings from past study participants. Pilot testing showed these postings to be interesting and easy to understand. The computer recorded the number of postings clicked on in the chat room (up to three links possible). The total number of links clicked on was calculated for each participant and submitted to analyses as an index of strategy use. Unfortunately, preliminary analyses suggested that the number of chat room visits was unaffected by the type of performance goal manipulation, achievement motivation, or the interaction between them, likely due to a floor effect. Thus, no further results are reported.

\section{Process Measures of Perceived Competence and Task Absorption}

Modeled after Harackiewicz and Elliot (1993), participants completed the new process measures by rating the extent to which they agreed with statements regarding the CAAT using a 7-point Likert scale. Specifically, items assessed perceived competence (4 items, $\alpha=.77$; e.g., "The CAAT was easy to understand") and task absorption ( 3 items, $\alpha=.61$, e.g., "While working on the task I lost track of time").

\section{Results and Discussion}

Again, we wanted to ensure that achievement motivation did not differ between conditions, and it did not, $F(1,54)=0.03, p=.87$, $R^{2}=.00$. Achievement motivation of participants randomly assigned to the performance-avoidance goal condition (overall, $M=$ $10.50, S D=2.43$; high achievement motivation, $M=12.91$; low achievement motivation, $M=8.94$ ) was statistically similar to participants randomly assigned to the performance-approach goal condition (overall, $M=10.58, S D=3.66$; high achievement motivation, $M=13.63$; low achievement motivation, $M=8.00$ ).

One of the goals of Study 3 was to examine whether being assigned performance-approach and performance-avoidance goals under conditions that trigger the stereotype was associated with different levels of interest for women higher and lower in achievement motivation. A second aim was to examine the hypothesized process through which these goals might be associated with differential interest. In particular, we wished to compare processes related to perceptions of competence at the task to processes that would be primarily related to the experience of interest while performing the task itself (task absorption). For clarity and consistency, ANOVA results are presented (similar to Study 1 and Study 2). However, in line with our second study aim, multiple regression analyses were also used to obtain the regression coefficients needed to examine the possible role of the two different process variables on the experience of interest in a stereotype threat context.

For the regression analyses, a direct effects basic model was first tested that included three terms entered simultaneously: the main effect of the performance goal conditions (performance goal type: performance avoidance $=1$, performance approach $=-1$ ); the main effect of achievement motivation (high achievement motivation $=1$, low achievement motivation $=-1$ ); and the performance goal-achievement motivation interaction term. All dependent measures were centered.

\section{Direct Effects on Immediate Interest}

A 2 (high achievement motivation vs. low achievement motivation) $\times 2$ (performance-avoidance goal vs. performanceapproach goal) ANOVA was performed on reported interest. Results yielded a significant interaction between goal condition and achievement motivation, $\beta=-.36, F(1,48)=11.52, p=.001$, $R^{2}=.22$. Follow-up simple effects analyses revealed that, as found in Study 1, women higher in achievement motivation reported relatively greater immediate interest in the stereotyped task when assigned performance-approach as opposed to performanceavoidance goals. In contrast, women lower in achievement motivation showed the opposite pattern, such that they reported lower interest when assigned performance-approach versus performanceavoidance goals (see Table 3).

\section{Direct Effects on Process Measures}

Effects on perceived competence. Results yielded a nonsignificant interaction between achievement motivation and type of performance goal, $\beta=-.27, F(1,48)=3.83, p=.056, R^{2}=.08$. The pattern of results was similar to those found for interest. Among the high achievement motivation participants, the highest levels of perceived competence were reported for those in the performance-approach goal condition, although this difference was not statistically significant as determined by simple effect analyses, $F(1,48)=2.91, p=.09, R^{2}=.11$. In contrast, among the low achievement motivation participants, no significant difference was found between performance-avoidance goal and performanceapproach goal conditions $(p=.31)$, even though participants tended to report higher levels of perceived competence in the performance-avoidance goal condition (see Table 3).

Effects on task absorption. Results yielded a significant interaction between achievement motivation and type of performance goal, $\beta=-.34, F(1,48)=12.97, p=.001, R^{2}=.21$. The pattern of simple effects results was similar to those found for interest. Among the high achievement motivation participants, the greatest levels of task absorption were reported for those assigned performance-approach versus performance-avoidance goals. In contrast, among the low achievement motivation participants, the greatest levels of task absorption were reported for those assigned performance-avoidance versus performance-approach goals. 
Table 3

Study 3: Mean Interest, Perceived Competence, and Task Absorption Ratings Under Stereotype Threat as a Function of Achievement Motivation and Goal Condition

\begin{tabular}{|c|c|c|c|c|c|c|}
\hline \multirow[b]{3}{*}{ Goal condition } & \multicolumn{6}{|c|}{ Achievement motivation } \\
\hline & \multicolumn{3}{|c|}{ Higher } & \multicolumn{3}{|c|}{ Lower } \\
\hline & $n$ & $M$ & $S D$ & $n$ & $M$ & $S D$ \\
\hline \multicolumn{7}{|c|}{ Interest } \\
\hline Performance-avoidance goal & 14 & $2.76_{\mathrm{a}}$ & 1.04 & 16 & $3.25_{\mathrm{a}}$ & 1.09 \\
\hline Performance-approach goal & 13 & $3.84_{b}$ & 0.99 & 13 & $2.33_{\mathrm{c}}$ & 1.05 \\
\hline \multicolumn{7}{|c|}{ Perceived competence } \\
\hline Performance-avoidance goal & & 2.75 & 1.53 & & 3.25 & 0.95 \\
\hline Performance-approach goal & & 3.68 & 1.52 & & 2.77 & 1.22 \\
\hline \multicolumn{7}{|c|}{ Task absorption } \\
\hline Performance-avoidance goal & & $3.15_{\mathrm{a}}$ & 1.44 & & $4.43_{c}$ & 1.30 \\
\hline Performance-approach goal & & $4.54_{b}$ & 1.32 & & $3.18_{\mathrm{d}}$ & 1.17 \\
\hline
\end{tabular}

Note. Columns and rows within each variable not sharing a subscript differ at $p<.05$. Simple effects are not provided for the perceived competence means because the interaction effect was nonsignificant.

\section{Overall Mediational Analysis}

The above results illustrate the outcomes associated with different goal assignments while under stereotype threat. High achievement motivation participants working on a stereotype-relevant computer science task have lower interest in the task when assigned a performance-avoidance goal compared with when assigned a performance-approach goal, whereas low achievement motivation participants showed the opposite pattern. Next, we examined perceived competence and task absorption process variables simultaneously to test for the contribution of each in mediating the relationship of the achievement motivation by type of performance goal interaction on the experience of interest. The two main effect terms of perceived competence and task absorption were each added to the direct effects basic model described above, and this new six-term process model was regressed on interest (Hoyle \& Robinson, 2004; Judd \& Kenny, 1981). ${ }^{3}$

The resulting six-term process model was significant overall, $F(5,44)=12.01, p=.000$, and accounted for significantly more variance than did the direct effects basic model, $\Delta F(2,42)=$ 22.21, $p=.000, \Delta R^{2}=.43$. Task absorption $(\beta=.60, p=.000)$ was significant in this model and accounted for the most variance in the model, such that the greater reported task absorption while working on the task, the greater the reported interest. Perceived competence accounted for less variance in the model compared with task absorption, although it was also significant $(\beta=.30, p=$ .01 ), such that greater perceived competence was associated with greater interest. Of importance, the Performance Goal $\times$ Achievement Motivation interaction effect on interest was no longer significant (from $\beta=-.36$ to $\beta=-.04, p=.72$ ). A Sobel test, using the unstandardized regression coefficients and error terms (MacKinnon, Warsi, \& Dwyer, 1995), showed the mediational effect of perceived competence on interest was not statistically different from zero $(\mathrm{Z}=1.30, p=.19)$, although the mediation effect of task absorption on interest was statistically significantly different from zero $(\mathrm{Z}=2.36, p=.012)$.

\section{Summary}

Taken together, results suggest that neither of the manipulated goals was ideal for all participants. Rather, similar to past work, relatively optimal goal assignment depended on the participant's level of achievement motivation (e.g., Barron \& Harackiewicz, 2001). Study 3 results suggest that when high and low achievement motivation participants were explicitly assigned performanceavoidance goals under conditions of gender-stereotype salience, it was primarily high achievement motivation participants who showed negative effects. In fact, even though low achievement motivation participants rarely adopted performance-avoidance goals spontaneously in Study 2, Study 3 results suggest that if they do, the avoidance goals may actually have positive effects.

Study 3 extended the results of Studies 1 and 2 by examining potential process variables. The overall process of task engagement was characterized by perceived competence and task absorption. Under stereotype conditions, compared with women lower in achievement motivation, women higher in achievement motivation assigned a performance-avoidance goal reported relatively lower levels of each of the process variables, which is important because

\footnotetext{
${ }^{3}$ To address whether the predicted process variables affected interest differently as a function of achievement motivation, we also created interaction terms to test whether achievement motivation interacted with perceived competence or task absorption to predict the experience of interest. Regression analyses showed no statistically significant effects. Thus, in consideration with our other findings, we can conclude that the process variables had the same effect on interest for both high and low achievement motivation, with different performance goals predicting the experience of the task.
} 
the process variables positively predicted interest in the task. Moreover, task absorption (and, to a lesser extent, perceived competence) was found to mediate the interactive effect of achievement motivation and goal assignment on the experience of interest. Thus, task absorption was distinct from performance-related processes in predicting the negative motivational effects of gender competence stereotypes.

\section{General Discussion}

Drawing from the STEP model (Smith, 2004, 2006), we examined the possibility that the presence of a stereotype and one's level of achievement motivation may influence the achievement goals adopted (assigned and spontaneous) in the situation, which in turn may affect motivational processes and outcomes. Three studies were conducted in which women were faced with a negative math stereotype while engaged in a math-related task (i.e., computer science). Study 1 showed that for women higher in achievement motivation, interest was lowest under stereotype threat when participants were assigned a performance-avoidance goal or when there was no explicit goal assigned, suggesting that participants may have spontaneously adopted performance-avoidance goals. Support for this notion was found in Study 2, which showed that the effects of stereotype threat on spontaneous achievement goal adoption depended on the individual's characteristic achievement motivation. Participants higher in achievement motivation were relatively more likely to adopt performance-avoidance goals under explicit or implicit stereotype threat than when the threat was nullified (Smith \& White, 2002). Participants lower in achievement motivation showed the opposite pattern. In addition, although the stereotype information had no differential impact on adoption of performance-approach goals for those higher in achievement motivation, participants lower in achievement motivation were surprisingly relatively more likely to adopt performance-approach goals under stereotype threat than when the threat was nullified. The pattern of goal adoption is important, in light of the results of Study 3, which showed that assigning performance goals to high and low achievement motivation participants differentially affected the process of task engagement. The effects of the manipulated performance goals (performance approach or performance avoidance) interacted with achievement motivation orientation to predict interest in the computer science task through perceptions of task absorption and, to a lesser extent, perceived competence.

In Study 1 and Study 3, we assigned participants an achievement goal under stereotype threat and measured the impact on interest. However, in Study 2, we measured the goal spontaneously adopted under stereotype threat but not the resulting interest. As suggested by Barron and Harackiewicz (2001), achievement goals may have different effects on interest as a function of one's achievement motivation and how the goals are adopted: spontaneously or experimentally assigned. The current work suggests that the presence of a stereotype may also influence this process. This raises several intriguing future research questions regarding achievement goals and interest. What are the possible differences between spontaneously adopted goals and assigned goals in general (Barron \& Harackiewicz, 2001), and do these differences occur in a stereotype context? Do spontaneous and assigned goals interact to form multiple goals (e.g., Harackiewicz et al., 1997; Pintrich, 2000), or does an assigned goal override or interfere with a spontaneously adopted goal (Dweck \& Elliott, 1983)?

The results for the current studies may be limited to college women relatively young in their careers. Our approach was to examine women who might (in theory) be open to considering a computer science major, because we desired to test our predictions with people for which there was less chance that previous experiences with the domain would influence their responses in the experimental setting. Yet, these recruitment criteria also limited our sample size, which likely influenced our statistical power and ability to draw firm conclusions.

\section{Importance of Achievement Motivation}

It is important to note that because our participants were all students and because within the university context achievement is emphasized, it is likely our classification of people higher and lower in achievement motivation was at the high end of the possible distribution. As such, the distinction between higher and lower achievement motivation is necessarily relative. Nevertheless, there are a number of potential explanations for why achievement motivation is an important moderator in the stereotyped task engagement process. It is possible that higher achievement motivation participants might buckle under an explicit achievement or evaluative pressure because they worry about not meeting expectations (and thus perhaps not living up to their positive reputation; e.g., Ho, Driscoll, \& Loosbrock, 1998; Smith \& Johnson, 2006). Individuals higher in achievement motivation might become preoccupied with trying to suppress the source of the pressure or evaluation (e.g., Senko \& Harackiewicz, 2002) and might subsequently have fewer resources available to work on the task (e.g., Schmader \& Johns, 2003). In comparison, lower achievement motivation participants might feel liberated by the explicit achievement expectations because they do not have to worry about not meeting expectations (i.e., both personal and external success was not expected from them), thus benefiting from the performance-avoidance goal (Senko \& Harackiewicz, 2002; cf. Jones \& Berglas, 1978). A caveat to this possibility is the findings of Sansone (1986), which showed that although receiving negative performance feedback actually led to lower achievementmotivated individuals caring more about their performance, caring about performance led to decreased interest for both higher and lower achievement-motivated individuals in contexts that explicitly linked performance to important abilities. Thus, it may be precisely because achieving is not typically part of lower achievement-motivated individuals' self-concept that a performance-avoidance goal may be associated with greater interest. If the task or context leads these individuals to see performance as involving important aspects of self, then the same goal may be associated with lower interest.

These explanations may be useful for understanding why achievement motivation is an important individual difference in the STEP. More than likely, some combination of these factors is important at different points during the task engagement process. The notion that a task is fluid and that change (e.g., in task meaning, in cognizance of evaluation) can take place during task engagement is pivotal to understanding the motivational outcomes associated with (stereotyped) task participation (e.g., Sansone \& Smith, 2000; Sansone, Weir, Harpster, \& Morgan, 1992). 


\section{Performance and Motivation}

We do not want to suggest that effects of stereotypes on performance are not important in their own right. However, the current research has demonstrated that stereotypes can have negative effects on motivational processes and outcomes separate from any effects they may have on performance or performancerelated processes. Furthermore, the nature of these effects may differ as a function of characteristic achievement orientations.

Our focus was to demonstrate the far right paths in Figure 1. Not pictured in Figure 1, however, nor examined in the present research, are the possible relationships between performance and interest and how these relationships may change over time and as a function of achievement orientation. For example, when individuals are interested in a topic, they show greater attention to and retention of the material and persist longer on the task (see Sansone \& Thoman, 2005, for a review). Alternatively, performing well (and believing that one is performing well) typically predicts greater interest. The function of perceived competence in the STEP merits additional research. For example, the current project did not provide participants with any indicators of performance at any time during the session. Participants' own feelings of competence posttask, however, predicted how interesting they found the task. We would expect that the timing and nature of competence feedback to participants might serve to attenuate or accentuate stereotype threat effect on interest, and this again would likely be moderated by achievement motivation.

Thus, although we have portrayed the interest and performance pathways separately, they may be sequentially related over time. This relationship over time may be particularly important when one examines the possibility of self-regulation of motivation. Sansone and colleagues have noted the potential trade-offs between doing something to make a currently boring but important task more interesting and indices of performance (Sansone et al., 1992; 1999). In particular, if the strategies that might make a task more interesting take time, attention, or effort away from the things that maximize performance, then performance may be hurt. On the other hand, forgoing the use of interest-enhancing strategies might maintain performance but lead to disengagement because of lower interest. We have previously argued that this trade-off may be particularly salient when individuals from diverse backgrounds are attempting to maintain optimal motivation and performance in domains that have previously been dominated by another culture. For example, women and individuals from more interdependent cultures may be more likely to want to work with or talk to others as a way to build and maintain interest (Thoman, Sansone, \& Pasupathi, in press). If tasks in particular domains are already constructed in ways that explicitly or implicitly discourage interpersonal interaction, then their preferred mode of interest regulation will be blocked. This was part of the reasoning for our including the ostensible chat room in Study 3, albeit there were no effects involving this variable. More research is needed to ferret out these possibilities.

\section{Women in Math and Science Fields}

This article began by outlining that because of negative stereotypes, women tend not to select or persist in mathematics, science, and related fields, even if they are highly capable of performing well. In computer science specifically, women are vastly underrepresented (e.g., American Association of University Women, 2000; Dryburgh, 2000; Glazer, 2005; National Center for Education Statistics, 2003). Although women may enroll in introductory classes or initially select to major in math-related domains, they exhibit a significantly higher dropout percentage rate than men (e.g., Seymour, 1999; Strenta, Elliott, Matier, Scott, \& Adair, 1993; see also Brainard, Metz, \& Gillmore, 2000). Thus, women who do self-select into and persist in a computer science class likely have a higher level of individual interest, and thus their situational interest may be less affected by knowledge of stereotypes (Renninger, Sansone, \& Smith, 2004). Indeed, it would be useful to test the STEP model with college women who do and do not drop out of the computer science major, and future research will benefit from such an endeavor.

The current research may give some insights into how to halt or reverse the underrepresentation of women in math-related fields. Intervention programs that focus on performance or competence issues may overlook the importance of enhancing interest in the domain. For example, if women are encouraged to self-regulate interest, even if it harms short-term performance, they may be more likely to pursue the domain over time (e.g., Sansone et al. 1992).

In addition, the STEP model (Smith, 2004) intentionally highlights achievement goals. However, other types of goals may be important to consider (e.g., interpersonal goals; Dowson \& McInerney, 2003). For instance, one speculation is that women who do persist in male-dominated areas such as computer science and math do so at the expense of interacting with other women in the male-dominated field, receiving social support from other women in the field, or forming an attachment with other women in the field (e.g., Hess \& Miura, 1985; J. Steele, James, \& Barnett, 2002). Deprivation of any of these factors has been shown to be related to a number of undesirable psychological and physiological effects (e.g., Cross \& Vick, 2001; Uchino, Cacioppo, \& Kiecolt-Glaser, 1996) and, as discussed previously, may itself lead to lower interest in the activities. Perhaps women in male-dominated areas do not affiliate with other women in the field for fear of being implicated by a negative gender stereotype association (Heilman, Wallen, Fuchs, \& Tamkins, 2004). Intervention programs (such as the Women in Engineering Initiative) that recruit and consistently make contact with women in male-dominated fields appear to provide a safe and structured environment for women to interact and consequently enhance field retention rates (e.g., Brainard \& Carlin, 1998; Downing, Crosby, \& Blake-Beard, 2005). An intriguing area for future research is in understanding the influence of interpersonal goals, the various ways that women in maledominated areas can meet those goals, and how those goals might influence the domain experience.

\section{Conclusion}

This project placed the body of prior work in stereotype threat, achievement goal theory, achievement motivation, and intrinsic motivation into an integrative framework. In so doing, the research helps to broaden our understanding of how competence-based stereotypes can influence individuals' motivation to select or persist on tasks in the stereotyped domain, whether or not there is a real basis for the stereotype. In particular, the research highlights 
the need to include interest as well as performance variables as outcomes that can be affected by knowledge of the stereotypes and begins to document the psychological processes involved. The current investigation presented the first empirical test of the notion that depending on an individual's achievement motivation, the effects of negative competence stereotypes can combine with and influence achievement goal adoption. These goals, in turn, influence interest in the stereotype-related task and do so differently as a function of characteristic differences in achievement motivation. The present research not only evidenced further support for the STEP as an important model for understanding the effects of goals and stereotypes but also points to opportunities for educational applications.

\section{References}

American Association of University Women. (2000). Tech-savvy: Educating girls in the new computer age. Washington, DC: AAUW Educational Foundation.

Aronson, J., Lustina, M. J., Good, C., Keough, K., Steele, C. M., \& Brown, J. (1999). When White men can't do math: Necessary and sufficient factors in stereotype threat. Journal of Experimental Social Psychology, $35,29-46$.

Barron, K. E., \& Harackiewicz, J. M. (2001). Achievement goals and optimal motivation: Testing multiple goal models. Journal of Personality and Social Psychology, 80, 706-722.

Benbow, C. P., \& Stanley, J. C. (1980, December 12). Sex differences in mathematical ability: Fact or artifact? Science, 210, 1262-1264.

Blanton, H., Crocker, J., \& Miller, D. T. (2000). The effects of in-group versus out-group social comparison on self-esteem in the context of a negative stereotype. Journal of Experimental Social Psychology, 36, 519-530.

Bleeker, M. M., \& Jacobs, J. E. (2004). Achievement in math and science: Do mothers' beliefs matter 12 years later? Journal of Educational Psychology, 96, 97-109.

Brainard, S. G., \& Carlin, L. (1998). A six-year longitudinal study of undergraduate women in engineering and science. Journal of Engineering Education, 87, 369-375.

Brainard, S. G., Metz, S. S., \& Gillmore, G. M. (2000). WEPAN pilot climate survey: Exploring the environment for undergraduate engineering students. Retrieved November 13, 2000, from http://www .wepan.org/associations/5413/files/Climate\%20Survey.pdf

Carver, D. L. (2000). Virtual workshop report: Research foundations for improving the representation of women in the information technology workforce. Arlington, VA: National Science Foundation, Directorate for Computer and Information Science and Engineering.

Chamberlin, J. (2003, September). Study offers clues on why women choose medicine over engineering. Monitor on Psychology, 34(3), 13.

Crocker, J., Major, B., \& Steele, C. (1998). Social stigma. In D. T. Gilbert, S. T. Fiske, \& G. Lindzey (Eds.), The handbook of social psychology (4th ed., Vol. 2, pp. 504-553). Boston, MA: McGraw-Hill.

Cross, S. E., \& Vick, N. V. (2001). The interdependent self-construal and social support: The case of persistence in engineering. Personality and Social Psychology Bulletin, 27, 820-832.

Csikszentmihalyi, M. (1978). Intrinsic rewards and emergent motivation. In M. R. Lepper \& D. Greene (Eds.), The hidden costs of reward (pp. 205-216). Hillsdale, NJ: Erlbaum.

Cury, F., Elliot, A., Sarrazin, P., Fonseca, D. D., \& Rufo, M. (2002). The trichotomous achievement goal model and intrinsic motivation: A sequential mediational analysis. Journal of Experimental Social Psychology, 38, 473-481.

Downing, R. A., Crosby, F. J., \& Blake-Beard, S. (2005). The perceived importance of developmental relationships on women undergraduates' pursuit of science. Psychology of Women Quarterly, 29, 419-426.
Dowson, M., \& McInerney, D. M. (2003). What do students say about their motivational goals? Towards a more complex and dynamic perspective on student motivation. Contemporary Educational Psychology, 28, $91-$ 113.

Dryburgh, H. (2000). Underrepresentation of girls and women in computer science: Classification of 1990 s research. Journal of Computing Research, 23, 181-202.

Dweck, C. S., \& Elliott, E. S. (1983). Achievement motivation. In E. M Hetherington (Ed.), Handbook of child psychology: Socialization, personality, and social development (Vol. iv, pp. 643-691). New York: Wiley.

Eccles, J. S., Adler, T., \& Meece, J. L. (1984). Sex differences in achievement: A test of alternate theories. Journal of Personality and Social Psychology, 46, 26-43.

Elliot, A. J., \& Church, M. A. (1997). A hierarchical model of approach and avoidance achievement motivation. Journal of Personality and Social Psychology, 72, 218-232.

Elliot, A. J., \& Harackiewicz, J. M. (1996). Approach and avoidance achievement goals and intrinsic motivation: A mediational analysis. Journal of Personality and Social Psychology, 70, 461-475.

Elliot, A. J., \& McGregor, H. A. (2001). A $2 \times 2$ achievement goal framework. Journal of Personality and Social Psychology, 80, 501-519.

Elliot, A. J., \& Sheldon, K. M. (2002, February). Culture and motivation. Symposium conducted at the third annual meeting of the Society of Personality and Social Psychology, Savannah, GA.

Elliot, A. J., Shell, M. M., Henry, K. B., \& Maier, M. A. (2005). Achievement goals, performance contingencies, and performance attainment: An experimental test. Journal of Educational Psychology, 97, 630-640.

Elliott, E. S., \& Dweck, C. S. (1988). Goals: An approach to motivation and achievement. Journal of Personality and Social Psychology, 54, $5-12$.

Glazer, S. (2005). Gender and learning. CQ Researcher, 15, 445-467.

Graham, N. (1985). Introduction to computer science. St. Paul, MN: West.

Grant, H., \& Dweck, C. S. (2003). Clarifying achievement goals and their impact. Journal of Personality and Social Psychology, 85, 541-553.

Harackiewicz, J. M., Barron, K. E., Carter, S. M., Lehto, A. T., \& Elliot, A. J. (1997). Predictors and consequences of achievement goals in the college classroom: Maintaining interest and making the grade. Journal of Personality and Social Psychology, 73, 1284-1295.

Harackiewicz, J. M., Barron, K. E., \& Elliot, A. J. (1998). Rethinking achievement goals: When are they adaptive for college students and why? Educational Psychologist, 33, 1-21.

Harackiewicz, J. M., Barron, K. E., Pintrich, P. R., Elliot, A. J., \& Thrash, T. M. (2002). Revision of achievement goal theory: Necessary and illuminating. Journal of Educational Psychology, 94, 638-645.

Harackiewicz, J. M., \& Elliot, A. J. (1993). Achievement goals and intrinsic motivation. Journal of Personality and Social Psychology, 65, 904-915.

Harvard Crimson. (2005). President Summers' remarks at the National Bureau of Economic Research, Jan. 14, 2005. Retrieved February 20, 2005, from http://www.thecrimson.com/article.aspx?ref =505844

Heilman, M. E., Wallen, A. S., Fuchs, D., \& Tamkins, M. M. (2004). Penalties for success: Reactions to women who succeed at male gendertyped tasks. Journal of Applied Psychology, 89, 416-427.

Hess, R. D., \& Miura, I. T. (1985). Gender differences in enrollment in computer camps and classes. Sex Roles, 13, 193-203.

Ho, C. P., Driscoll, D. M., \& Loosbrock, D. (1998). Great expectations: The negative consequences of falling short. Journal of Applied Social Psychology, 28, 1743-1759.

Hoyle, R. H., \& Robinson, J. C. (2004). Mediated and moderated effects in social psychological research: Measurement, design, and analysis issues. In C. Sansone, C. C. Morf, \& A. T. Panter (Eds.), The Sage handbook of methods in social psychology (pp. 213-233). Thousand Oaks, CA: Sage. 
Inzlicht, M., \& Ben-Zeev, T. (2003). Do high-achieving female students underperform in private? The implications of threatening environments on intellectual processing. Journal of Educational Psychology, 95, 796805.

Isaac, J., Sansone, C., \& Smith, J. L. (1999). Other people as a source of interest in an activity. Journal of Experimental Social Psychology, 35, $239-265$.

Jackson, D. N. (1999). Personality Research Form manual. Goshen, NY: Research Psychologists Press. (Original work published 1974)

Jones, E. E., \& Berglas, S. (1978). Control of attributions about the self through self-handicapping strategies: The appeal of alcohol and the role of underachievement. Personality and Social Psychology Bulletin, 4, 200-206.

Judd, C. M., \& Kenny, D. A. (1981). Estimating the effects of social interventions. New York: Cambridge University Press.

Leyens, J. P., Desert, M., Croizet, J. C., \& Darcis, C. (2000). Stereotype threat: Are lower status and history of stigmatization preconditions of stereotype threat? Personality and Social Psychology Bulletin, 26, 1189-1199.

Linnenbrink, E. A. (2005). The dilemma of performance-approach goals: The use of multiple goal contexts to promote students' motivation and learning. Journal of Educational Psychology, 97, 197-213.

MacKinnon, D. P., Warsi, G., \& Dwyer, J. H. (1995). A simulation study of mediated effect measures. Multivariate Behavioral Research, 30, $41-62$.

Morgan, C., Isaac, J. D., \& Sansone, C. (2001). The role of interest in understanding the career choices of female and male college students. Sex Roles, 44, 295-320.

Mullis, I., Martin, M. O., Beaton, A. E., Gonzalez, E. J., Kelly, D. L., \& Smith, T. A. (1998). Mathematics and science achievement in the final year of secondary school: IEA's Third International Mathematics and Science Study. Chestnut Hill, MA: TIMMS International Study Center.

National Center for Education Statistics. (2003). Integrated postsecondary education data system: Fall 2002 survey. Washington, DC: U.S. Department of Education.

Nicholls, J. G. (1984). Achievement motivation: Conceptions of ability, subjective experience, task choice, and performance. Psychological Review, 91, 328-346.

Nosek, B. A., Banaji, M. R., \& Greenwald, A. G. (2002). Math = male, me $=$ female, therefore math $\neq$ me. Journal of Personality and Social Psychology, 83, 44-59.

Pintrich, P. R. (2000). Multiple goals, multiple pathways: The role of goal orientation in learning and achievement. Journal of Educational Psychology, 92, 544-555.

Renninger, K. A., Sansone, C., \& Smith, J. L. (2004). Love of learning. In C. Peterson \& M. E. P. Seligman (Eds.), Character strengths and virtues: A classification and handbook (pp. 161-179). New York: Oxford University Press.

Sansone, C. (1986). A question of competence: The effects of competence and task feedback on intrinsic interest. Journal of Personality and Social Psychology, 51, 918-931.

Sansone, C., \& Harackiewicz, J. M. (1996). "I don't feel like it": The function of interest in self-regulation. In L. L. Martin \& A. Tesser (Eds.), Striving and feeling: Interactions among goals, affect, and selfregulation (pp. 203-228). Mahwah, NJ: Erlbaum.

Sansone, C., \& Smith, J. L. (2000). Interest and self-regulation: The relation between having to and wanting to. In C. Sansone \& J. M. Harackiewicz (Eds.), Intrinsic and extrinsic motivation: The search for optimal motivation and performance (pp. 341-372). San Diego, CA: Academic Press.

Sansone, C., \& Thoman, D. B. (2005). Interest as the missing motivator in self-regulation. European Psychologist, 10, 175-186.

Sansone, C., \& Thoman, D. B. (in press). Maintaining activity engagement:
Individual differences in the process of self-regulating motivation. Journal of Personality.

Sansone, C., Weir, C., Harpster, L., \& Morgan, C. (1992). Once a boring task always a boring task? Interest as a self-regulatory mechanism. Journal of Personality and Social Psychology, 63, 379-390.

Sansone, C., Wiebe, D. J., \& Morgan, C. (1999). Self-regulating interest: The moderating role of hardiness and conscientiousness. Journal of Personality, 67, 701-733.

Schmader, T., \& Johns, M. (2003). Converging evidence that stereotype threat reduces working memory capacity. Journal of Personality and Social Psychology, 85, 440-452.

Schmader, T., Johns, M., \& Barquissau, M. (2004). The costs of accepting gender differences: The role of stereotype endorsement in women's experience in the math domain. Sex Roles, 50, 835-850.

Senko, C., \& Harackiewicz, J. M. (2002). Performance goals: The moderating roles of context and achievement orientation. Journal of Experimental Social Psychology, 38, 603-610.

Senko, C., \& Harackiewicz, J. M. (2005). Achievement goals, task performance, and interest: Why perceived goal difficulty matters. Personality and Social Psychology Bulletin, 31, 1739-1753.

Seymour, E. (1999). The role of socialization in shaping the career-related choices of undergraduate women in science, mathematics, and engineering majors. Annals of the New York Academy of Sciences: Vol. 869. Women in sciences and engineering: Choices for success (pp. 118-126). New York: New York Academy of Sciences.

Seymour, E., \& Hewitt, N. M. (1997). Talking about leaving: Why undergraduates leave the sciences. Boulder, CO: Westview Press.

Shih, M., Pittinsky, T. L., \& Ambady, N. (1999). Stereotype susceptibility: Identity salience and shifts in quantitative performance. Psychological Science, 10, 80-83.

Skaalvik, E. M. (1997). Self-enhancing and self-defeating ego orientation: Relations with task and avoidance orientation, achievement, selfperceptions, and anxiety. Journal of Educational Psychology, 89, 7181.

Smith, J. L. (2004). Understanding the process of stereotype threat: A review of mediational variables and new performance goal directions. Educational Psychology Review, 16, 177-206.

Smith, J. L. (2006). The interplay among stereotypes, performanceavoidance goals, and women's math performance expectancies. Sex Roles, 54, 287-296.

Smith, J. L., \& Johnson, C. S. (2006). A stereotype boost or choking under pressure? Positive gender stereotypes and men who are low in domain identification. Basic and Applied Social Psychology, 28, 51-63.

Smith, J. L., Morgan, C., \& White, P. H. (2005). Investigating a measure of computer technology domain identification: A tool for understanding gender differences and stereotypes. Educational and Psychological Measurement, 65, 336-355.

Smith, J. L., \& White, P. H. (2002). An examination of implicitly activated, explicitly activated, and nullified stereotypes on mathematical performance: It's not just a woman's issue. Sex Roles, 47, 179-191.

Spelke, E. S. (2005). Sex differences in intrinsic aptitude for mathematics and science? A critical review. American Psychologist, 60, 950-958.

Spencer, S. J., Steele, C. M., \& Quinn, D. M. (1999). Stereotype threat and women's math performance. Journal of Experimental Social Psychology, 35, 4-28.

Stangor, C., Carr, C., \& Kiang, L. (1998). Activating stereotypes undermines task performance expectations. Journal of Personality and Social Psychology, 75, 1191-1197.

Steele, C. M., \& Aronson, J. (1995). Stereotype threat and the intellectual test performance of African Americans. Journal of Personality and Social Psychology, 69, 797-811.

Steele, J., James, J. B., \& Barnett, R. C. (2002). Learning in a man's world: Examining the perceptions of undergraduate women in male-dominated academic areas. Psychology of Women Quarterly, 26, 46-50. 
Strenta, C., Elliott, R., Matier, M., Scott, J., \& Adair, R. (1993). Choosing and leaving science in highly selective institutions: General factors and the question of gender (Report to the Alfred P. Sloan Foundation). New York: Alfred P. Sloan Foundation.

Tauer, J. M., \& Harackiewicz, J. M. (2004). The effects of cooperation and competition on intrinsic motivation and performance. Journal of Personality and Social Psychology, 86, 849-861.

Thoman, D. B., Sansone, C., \& Pasupathi, M. (in press). Talking about interest: Exploring the role of social interaction for regulating motivation and the interest experience. Journal of Happiness Studies.

Uchino, B. N., Cacioppo, J. T., \& Kiecolt-Glaser, J. K. (1996). The relationship between social support and physiological processes: A review with emphasis on underlying mechanisms and implications for health. Psychological Bulletin, 119, 488-531.

Visser, P. S., Krosnick, J. A., \& Lavrakas, P. J. (2000). Survey research. In H. Reis \& C. Judd (Eds.), Handbook of research methods in social and personality psychology (pp. 223-252). New York: Cambridge University Press.

Wicherts, J. M., Dolan, C. V., \& Hessen, D. J. (2005). Stereotype threat and group differences in test performance: A question of measurement invariance. Journal of Personality and Social Psychology, 89, 696-716.

Wolters, C. A. (2004). Advancing achievement goal theory: Using goal structures and goal orientations to predict students' motivation, cognition, and achievement. Journal of Educational Psychology, 96, 236250.

Yopyk, D. A., \& Prentice, D. A. (2005). Am I an athlete or a student? Identity salience and stereotype threat in student-athletes. Basic and Applied Social Psychology, 4, 329-336.

Received August 9, 2005 Revision received September 12, 2006 Accepted October 3, 2006

\section{American Psychological Association SUbSCRIPTION Claims INFORMATION}

Today's Date:

We provide this form to assist members, institutions, and nonmember individuals with any subscription problems. With the appropriate information we can begin a resolution. If you use the services of an agent, please do NOT duplicate claims through them and directly to us. PLEASE PRINT CLEARLY AND IN INK IF POSSIBLE.

\begin{tabular}{llll}
\hline PRINT FULL NAME OR KEY NAME OF NNSTITUTION & & \\
\hline ADDRESS & & & \\
\hline & & & \\
\hline CITY & STATE/COUNTRY & ZIP
\end{tabular}

YOUR NAME AND PHONE NUMBER

TITLE

\section{MEMBER OR CUSTOMER NIMBER (MAY BEFOUND ONANY PAST ISSUE LABEL)}

\section{DATE YOUR ORDER WAS MAILED (OR PHONED)}

\section{PREPAID _ C CHECK _ CHARGE}

CHECK/CARD CLEARED DATE:

(If possible, send a copy, front and back, of your cancelled check to help us in our research of your claim.

ISSUES: _ MISSLNG _ DAMAGED
NUMBER OR MONTH

Thank you. Once a claim is received and resolved, delivery of replacement issues routinely takes 4-6 weeks.

(TO BE FILLED OUT BY APA STAFF)

DATE RECEIVED:

ACTION TAKEN:

STAFF NAME:
DATE OF ACTION:

INV. NO. \& DATE:

LABEL NO. \& DATE:

Send this form to APA Subscription Claims, 750 First Street, NE, Washington, DC 20002-4242

PLEASE DO NOT REMOVE. A PHOTOCOPY MAY BE USED. 